\title{
Voltammetric Behavior of Self-assembled Monolayers of Novel Nickel (II / III) Pentaazamacrocyclic Complex on Gold Electrode and Electrocatalytic Oxidation of Hydrogen Peroxide
}

\author{
K. Vengatajalabathy GOBI, Koichi TOKUDA and Takeo OHSAKA*
}

Received December 6, 1996 ; Accepted January 24, 1997

\section{INTRODUC'TION}

Surface-modified electrodes continue to be of interest for both fundamental and practical reasons ${ }^{1)}$. Among the many different chemical strategies that could be used to prepare such modified electrodes, monolayer self- assembly method is a most promising tool for constructing stable, well- defined monolayers on electrode surfaces with atomic resolution ${ }^{2)}$. Reports on the monolayer-immobilization of several redoxactive molecules on gold electrodes have appeared through this technique ${ }^{1)}$. Tetraazamacrocyclic complexes of transition metals have been proved to be effective electrocatalysts in the reduction of carbon dioxide, nitrate, nitrous oxide, oxygen and oxidation of hydrogen peroxide, cystine, glucose etc ${ }^{3}$. Especially the usually unstable oxidation states of transition metal ions ( $\mathrm{Ni}$ (III), $\mathrm{Ni}$ ( I ), $\mathrm{Co}$ (III), Co( I ), etc.) can be stabilized by complexing with polyazamacrocycles and the accession of those oxidation states can be modulated over a wide range ${ }^{3)}$. To introduce the monolayer of redox active nickel (II) complex on the electrode

Department of Electronic Chemistry, Interdisciplinary Graduate School of Scinece and Engineering, Tokyo Institute of Technology (4259 Nagatsuta, Midori- ku, Yokohama 226, JAPAN)

Key Words : Electroactive Self- assembled Monolayer, Nickel Complex, Hydrogen Peroxide Oxidation surface, we newly synthesized a bispentaazamacrocyclic dinickel( I) complex, 1(see Fig.1). The complex 1 was self- assembled with a coadsorbate, diphenyl disulfide, onto the gold electrode. In this short communication, we report the cyclic voltammetry of the selfassembly of 1 and its electrocatalytic activity towards hydrogen peroxide oxidation.

\section{EXPERIMENTAL}

The gold electrodes were prepared by sealing an annealed $1.0 \mathrm{~mm}$ diameter gold wire in an insulating poly(chlorotrifluoroethylene). After polishing the exposed gold surface with alumina powder $(1.0$ and $0.06 \mathrm{~mm})$, the electrodes were briefly etched in a 1:3:4 (in volume) mixture of conc. $\mathrm{HNO}_{3} / \mathrm{conc}$. $\mathrm{HCl} /$ water prior to immersion in a methanol solution containing a mixture of $0.15 \mathrm{mM}$ complex 1 and $0.03 \mathrm{mM}$ diphenyl disulfide. Electrodes were remained in the coating solution for at least $15 \mathrm{~h}$ and rinsed with methanol and water. Electrochemical mesurements were performed in a two-compartment three- electropde cell, using a computercontrolled electrochemical measuring system (BAS, 100B/W). An $\mathrm{NaCl}$ saturated $\mathrm{Ag} / \mathrm{AgCl}$ electrode was used as the reference electrode and a platinum wire as the counter electrode. 


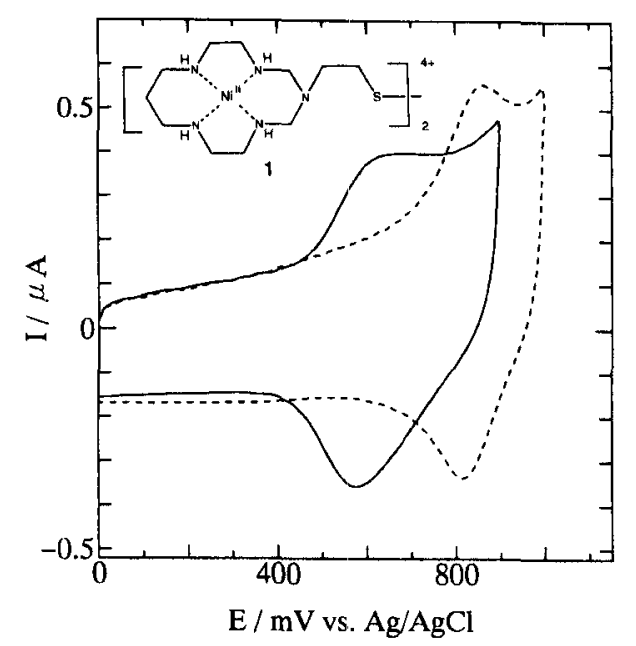

Fig. 1 Typical cyclic voltammograms of the self-assembly of 1 on gold electrode in $0.1 \mathrm{M}$ solution of $\mathrm{H}_{2} \mathrm{SO}_{4}(\longrightarrow)$ and $\mathrm{HNO}_{3}\left(----\rightarrow\right.$. Potential scan rate $: 500 \mathrm{mVs}^{-1}$.

\section{RESULTS AND DISCUSSION}

\subsection{Electrochemistry of the self-assembly of 1}

Figure 1 shows the cylic voltammograms of the self- assembly of 1 observed in $0.1 \mathrm{M}$ aqueous solutions of $\mathrm{H}_{2} \mathrm{SO}_{4}$ and $\mathrm{HNO}_{3}$. In both the supporting electrolyte solutions, the cyclic voltammetric behavior is clearly that of a surface-confined species undergoing reversible oxidation- reduction, as indicated by the symmetrical and reversible redox waves and small peak splitting ( $\triangle E \mathrm{p}<20 \mathrm{mV}$ ) between the anodic and cathodic peak potentials. The anodic and cathodic peak currents $\left(i_{\mathrm{p}}{ }^{\mathrm{a}}\right.$ and $\left.i_{\mathrm{p}}{ }^{\mathrm{c}}\right)$ are proportional to potential scan rate ranging from 0.1 to $2 \mathrm{Vs}^{-1}$ and the ratio of $i_{\mathrm{P}}^{\mathrm{a}}$ to $i_{\mathrm{P}}{ }^{\mathrm{c}}$ at a given scan rate is unity. Integration of the current peak yielded $6.9 \times 10^{-11} \mathrm{~mol} \mathrm{~cm}^{-2}$ as the surface coverage of the electroactive nickel complex, indicating that the distance between two nickel centers is ca. $16 \AA$. The formal potential $E^{\circ}$ (estimated as the average of the anodic and cathodic peak potentials) for the redox reaction of the immobilized nickel

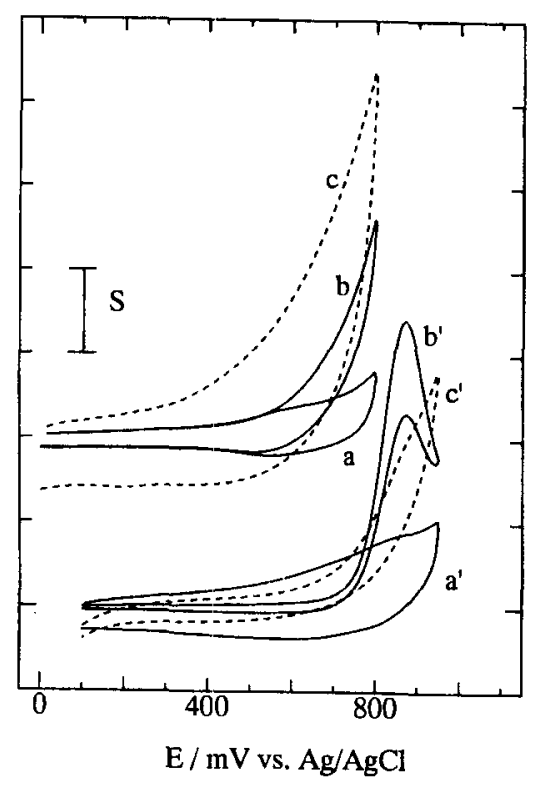

Fig. 2 Cyclic voltammograms of the self-assembly of 1 (a, $\left.a^{\prime}, b, b^{\prime}\right)$ and bare gold electrode (c, $\left.c^{\prime}\right)$ in the presence (b, b', $\left.c, c^{\prime}\right)$ and absence $\left(a, a^{\prime}\right)$ of $10 \mathrm{mM} \mathrm{H}_{2} \mathrm{O}_{2}$. Electrolyte: 0.1 $\mathrm{M} \mathrm{Na}_{2} \mathrm{SO}_{4}(\mathrm{pH} 3)(\mathrm{a}, \mathrm{b}, \mathrm{c}) ; 0.1 \mathrm{M} \mathrm{NaNO}_{3}(\mathrm{pH} 3)\left(\mathrm{a}^{\prime}, \mathrm{b}^{\prime}, c^{\prime}\right)$. Potential scan rate: $500 \mathrm{mV} \mathrm{s}^{-1}(\mathrm{a}, \mathrm{b}, \mathrm{c}) ; 100 \mathrm{mV} \mathrm{s}^{-1}$ ( $\mathrm{a}^{\prime}, \mathrm{b}^{\prime}$, $\left.\mathrm{c}^{\prime}\right)$. S: $0.4 \mu \mathrm{A}(\mathrm{a}, \mathrm{b}, \mathrm{c}) ; 0.25 \mu \mathrm{A}\left(\mathrm{a}^{\prime}\right) ; 1 \mu \mathrm{A}\left(\mathrm{b}^{\prime}, \mathrm{c}^{\prime}\right)$.

complex is more positive $(0.84 \mathrm{~V})$ in $0.1 \mathrm{M}$ $\mathrm{HNO}_{3}$ than that $(0.60 \mathrm{~V})$ in $0.1 \mathrm{M} \mathrm{H}_{2} \mathrm{SO}_{4}$. The change of the formal potential was reversible when the self-assembly electrode was moved between $\mathrm{H}_{2} \mathrm{SO}_{4}$ and $\mathrm{HNO}_{3}$ environments. The observed trend of anion-controlled shift in the formal potential of $\mathrm{Ni}$ ( II / III) redox couple may be due to the difference in coordinating tendency of $\mathrm{SO}_{4}{ }^{2-}$ and $\mathrm{NO}_{3}{ }^{-}$anions ${ }^{4}$, i.e., the oxidation of $\mathrm{Ni}(\mathrm{II})$ to $\mathrm{Ni}$ (III) is more favourable in $\mathrm{H}_{2} \mathrm{SO}_{4}$ than in $\mathrm{HNO}_{3}$.

\subsection{Electrocatalytic oxidation of $\mathrm{H}_{2} \mathrm{O}_{2}$}

The electrocatalytic activity of the selfassmebly towards the oxidation of $\mathrm{H}_{2} \mathrm{O}_{2}$ was investigated. Figure 2 shows the cyclic voltammograms of the self-assembly in an aqueous 0.1 
$\mathrm{M} \mathrm{NaNO}_{3}(\mathrm{pH}=3)$ solution in the presence and absence of $10 \mathrm{mM} \mathrm{H}_{2} \mathrm{O}_{2}$. In the presence of $\mathrm{H}_{2} \mathrm{O}_{2}$, an enormous increase in the anodic peak current was observed with the disappearance of the cathodic peak (Fig. 2b'). The coincidence of the oxidation of $\mathrm{H}_{2} \mathrm{O}_{2}$ with that of the $\mathrm{Ni}$ (II) complex as well as the disappearance of the $\mathrm{Ni}$ ( III) reduction peak clearly indicate that the electrooxidized $\mathrm{Ni}$ ( III) complex participates directly in the electrocatalytic oxidation of $\mathrm{H}_{2} \mathrm{O}_{2}$. At a bare gold electrode the oxidation peak of $\mathrm{H}_{2} \mathrm{O}_{2}$ could not be observed when probed in the same potential region (Fig.2 $\mathrm{c}^{\prime}$ ). Similarly the oxidation of $\mathrm{H}_{2} \mathrm{O}_{2}$ at the selfassembly electrode was pursued in an aqueous $0.1 \mathrm{M} \mathrm{Na}_{2} \mathrm{SO}_{4}(\mathrm{pH}=3)$ solution with or without $\mathrm{H}_{2} \mathrm{O}_{2}$ (Fig. 2). In the presence of $\mathrm{H}_{2} \mathrm{O}_{2}$, the cyclic voltammogram at the self- assembly electrode (Fig. $2 b$ ) resembles that observed at a bare gold electrode (Fig. 2c), except that a capacitive current is largely decreased at the former electrode. Thus, no electrocatalysis of the self- assembly of 1 for $\mathrm{H}_{2} \mathrm{O}_{2}$ oxidation was actually observed in $\mathrm{Na}_{2} \mathrm{SO}_{4}$ solution.
In conclusion, we can demonstrate that the formal potential of the self-assembly of 1 and its electrocatalytic activity for the oxidation of $\mathrm{H}_{2} \mathrm{O}_{2}$ greatly depend on the supporting electrolyte anion.

The present work was financially supported by a Grant-in-Aid for Scientific Research in Priority Areas of "New Polymer and Their NanoOrganized Systems" (No. 277/08246219) from the Ministry of Education, Science, Sports and Culture, Japan.

\section{REFERENCES}

1) A.Ulman, An Introduction to Ultrathin Organic Films, Academic press, San Diego, CA (1991).

2) R.W.Murray (Ed.), Molecular Design of Electrode Surfaces, Wiley, New York (1992).

3) E.Kimura, J. Coord, Chem., 15, 1 (1986).

4) M.D.Casa. L.Fabbrizzi, M.Mariani and B.Seghi, $J$ Chem. Soc., Dalton Trans., 55 (1990). 